\title{
Detection Of Mutated gyrA Gene From Nalidixic Acid Resistant Salmonella Typhi And Paratyphi A Isolated From Enteric Fever Patients In A Tertiary Care Hospital Of Bangladesh
}

\author{
Maiz-ul Ahad Suman ${ }^{1}$, Md. Abdullah Siddique ${ }^{2}$, SM Shamsuzzaman ${ }^{3}$, Abu Rayhan Khandakar ${ }^{4}$, Faiz Ahmed Khondaker ${ }^{5}$ \\ Sharmin Akter Sumi ${ }^{6}$, Roushan Jahan ${ }^{7}$ \\ ${ }^{1}$ Department of Microbiology, Gonoshasthaya Samaj Vittik Medical College, Dhaka. ${ }^{2}$ Department of Microbiology, Barind \\ Medical College, Rajshahi. ${ }^{3}$ Department of Microbiology, Dhaka Medical College. ${ }^{4}$ Department of Biochemistry, Rajshahi \\ Medical College. ${ }^{5}$ Department of Hepatology, Shaheed Suhrawardy Medical College. ${ }^{6}$ Department of Burn and plastic \\ surgery, Dhaka Medical College. ${ }^{7}$ Department of Pediatrics, BSMMU
}

Submitted on: 28 September, 2015. Accepted on: 22 November, 2015

\begin{abstract}
A cross sectional study for the detection of empirically used antibiotic resistant Salmonella was carried out in the department of microbiology of Rajshahi Medical College (RMC) and PCR and DNA sequencing were done in the department of microbiology of Dhaka Medical College during the period from August 2014 to July 2015.Total 323 blood samples were collected from suspected enteric fever patients from medicine and paediatric units of RMC hospital and cultured on brain heart infusion broth for isolation of Salmonella. Identification of Salmonella was done by biochemical tests and final identification was done by specific antisera. Antimicrobial sensitivity test was done by disc diffusion technique. PCR was used to detect gyrA gene. Sequencing of the gyrA gene was done to see mutation. Culture yielded growth of Salmonella typhi in 11 (36.67\%) and Salmonella paratyphi A in 19(63.33\%) samples. Among 11 Salmonella typhi, 8(72.73\%) were resistant to nalidixic acid, 2(18.18\%) to ciprofloxacin and one (9.09\%) to ofloxacin. Among 19 Salmonella paratyphi A, all (100\%) were resistant to nalidixic acid, 4(21.05\%) to ofloxacin, and 3(15.79\%) to ciprofloxacin. All the Salmonella typhi and Salmonella paratyphi A were gyrA gene positive. All the nalidixic acid resistant strains of Salmonella typhi and Salmonella paratyphi $A$ were mutated at amino acid position 83 by replacing serine with phenylalanine. None of the nalidixic acid sensitive Salmonella strain had mutated gyrA gene.
\end{abstract}

Key word: Bangladesh, gyrA gene mutation, nalidixic acid resistance, Salmonella typhi, Salmonella paratyphi A.

\section{INTRODUCTION}

Enteric fever (typhoid and paratyphoid fever) is an endemic disease in developing countries ${ }^{1}$. The etiological agent of typhoid fever is Salmonella typhi and paratyphoid fevers are Salmonella paratyphi $A, B$ and $C^{2}$. Among these Salmonella, Salmonella typhi and Salmonella paratyphi $A$ are mainly responsible for enteric fever. Antibiotic is the main therapeutic option for the treatment of enteric fever and mortality rate may reach up to $30 \%$ in the absence of effective antibiotic therapy ${ }^{3}$. Since Salmonella are resistant to conventional antibiotics (ampicillin, chloramphenicol and cotrimoxazole), ciprofloxacin and ofloxacin had been the drugs of choice in Bangladesh4. But rampant use of ciprofloxacin made Salmonella typhi and Salmonella paratyphi A resistant

$\triangle \square$ Correspondence:

Dr. Maiz-ul Ahad Suman

Senior Lecturer

Department of Microbiology

Gonoshasthaya Samaj Vittik Medical College, Dhaka

Phone number: 01798638986

E-mail: sumanmaiz@yahoo.com to nalidixic acid by mutation in gyrA gene which replace nalidixic acid from the target site in gyrase $\mathrm{A}^{5,3}$. These nalidixic acid resistant Salmonella are also less responsive to ciprofloxacin due to less hydrogen bonding formed between ciprofloxacin and altered gyrase A. Resistance of Salmonella to nalidixic acid is mediated by alteration of amino acid in DNA gyrase which is result of mutation in $g y r A$ and $g y r B$ chromosomal genes and by alteration of amino acid in tropoisomerase which is result of mutation in parE and perC genes or by decreased permeability of drug or over-expression of efflux pump. However, mutation in gyrA gene is more common than $\operatorname{gyr} B$, parE and perC genes ${ }^{6}$. Resistance mutations in gyrA gene is clustered in a region of gene product 67-106 amino acids called quinolone resistancedetermining region and most common mutations associated with quinolone resistance are located in amino acid, serine-83 or aspartic acid-877. Single mutation in $g y r A$ gene (either amino acid serine-83 or aspartic acid-87) is associated with resistance to nalidixic acid and decreased susceptibility to 
fluoroquinolone ${ }^{8}$.

A good number of quinolone resistant Salmonella have been detected in Rajshahi Medical College Hospital but the reason behind this resistance has not been clear. So this study has been carried out to find out the mutations in gyrA gene from nalidixic acid resistant Salmonella.

\section{MATERIALS AND METHODS}

Microbiological study was carried out in the department of microbiology of Rajshahi Medical College (RMC) and PCR and sequencing was performed in the department of microbiology of Dhaka Medical College from August 2014 to July 2015. Blood samples were collected from 323 suspected enteric fever patients of both outpatient and inpatient departments of medicine and pediatric units of RMC hospital. Patients presented with fever $2102^{\circ} \mathrm{F}$ for more than 3 days and associated constipations, diarrhea, diffuse abdominal pain or coated tongue were clinically diagnosed as enteric fever and were included in this study.

About $5 \mathrm{ml}$ blood from adult and 1 to $5 \mathrm{ml}$ blood (according to body weight) from young children were collected following preparation of the skin site with $70 \%$ alcohol, then providone iodine and transferred to blood culture bottles containing 50 and $25 \mathrm{ml}$ brain heart infusion broth respectively. The bottles containing blood were sent to laboratory promptly and incubated at $37^{\circ} \mathrm{C}$.

The culture bottles were examined daily for visible turbidity and subcultured every alternate day on blood, MacConkey and Salmonella-Shigella agar up to 14 days. Bacterial growth was indicated by the presence of turbidity in the media. If visible growth was detected a little amount of the broth was dispensed by sterile disposable syringe and inoculated on blood, MacConkey and Salmonella-Shigella agar and incubated at $37^{\circ} \mathrm{C}$ for 24 hours. If growth observed on blood, MacConkey and Salmonella-Shigella agar media, bacteria were identified as Salmonella typhi and Salmonella paratyphi $A$ by nonlactose fermenting colony on MacConkey agar media, gram negative bacilli in Gram stained smear, motile, indole, urease and citrate negative, alkaline slant and acid butt with or without $\mathrm{H}_{2} \mathrm{~S}$ production in triple sugar iron agar media, negative oxidase test and finally agglutination with Salmonella polyvalent $\mathrm{O}$ and specific $\mathrm{H}$ antisera. Antimicrobial susceptibility was determined by modified Kirby-Bauer disc diffusion method and following Clinical and Laboratory Standards Institute (CLSI) guide line using Mueller-Hinton agar plate ${ }^{9}$. Both Salmonella typhi and paratyphi $A$ were tested for susceptibility with ciprofloxacin $(5 \mu \mathrm{g})$, ofloxacin $(5 \mu \mathrm{g})$ and nalidixic acid $(30 \mu \mathrm{g})$. A representative disc of each batch was tested with ATCC
25922 strain of Escherechia coli to assess the quality of the test. Disc diffusion test was interpreted according to CLSI (2013) and European Committee on Antimicrobial Susceptibility Testing, 2015.

Preservation of bacteria: The bacteria was streaked on nutrient agar slope and incubated at $37^{\circ} \mathrm{C}$. When visible growth was observed, sterile liquid paraffin was poured on slope to cover the agar. The tube containing growth was then preserved at $4^{\circ} \mathrm{C}^{10}$.

\section{Detection of gyrA gene by polymerase chain reaction:}

Formation of pellet of Salmonalla ${ }^{11}$ : The nalidixic acid resistant and sensitive Salmonella typhi and Salmonella paratyphi A were tested for gyrA gene by PCR using previously used primer, forward $5^{\prime}$ TGTCCGAGATGGCCTGAAGC-3' reverse 5'CGTTGATGACTTCCGTCAG-3'. The bacteria were cultured in brain heart infusion broth within micro centrifuge tube and incubated at $37^{\circ} \mathrm{C}$ for 24 hours. The microcentrifuge tube was centrifuged at $4000 \mathrm{x} \mathrm{g}$ for 10 minutes and supernatant was discarded. The pellets were then preserved at $-20^{\circ} \mathrm{C}$ for DNA extraction.

DNA extraction: The Salmonella pellets were suspended with $300 \mu \mathrm{l}$ of sterile distilled water and vortexed well. The microcentrifuge tube was placed on heat block at $100^{\circ} \mathrm{C}$ for 10 minutes and then immediately placed on ice block for 5 minutes. The microcentrifuge tube was then centrifuged at $13000 \mathrm{x} \mathrm{g}$ at $4^{\circ} \mathrm{C}$ for 6 minutes and the supernatant was transferred to another fresh microcentrifuge tube. This supernatant contains extracted DNA which was used as template DNA for PCR.

Mixing of master mix, primer and extracted DNA: A total of $25 \mu \mathrm{l}$ of reaction mixture was prepared in a PCR tube by using $12.5 \mu \mathrm{l}$ of master mix (a mixture of dNTP, taq polymerase, $\mathrm{MgCl}_{2}, \mathrm{PCR}$ buffer), $1 \mu \mathrm{l}$ of forward primer, 1 $\mu l$ of reverse primer, $3 \mu \mathrm{l}$ of extracted DNA and $7.5 \mu 1$ nuclease free water.

Amplification in thermal cycler: After initial denaturation at $94^{\circ} \mathrm{C}$ for 3 minutes, total 30 cycles of each cycle consists of denaturation at $94^{\circ} \mathrm{C}$ for one minute, annealing at $55^{\circ} \mathrm{C}$ for one minute and extension at $72^{\circ} \mathrm{C}$ for one minute with one cycle of final extension at $72^{\circ} \mathrm{C}$ for 10 minutes.

Gel electrophoresis: Electrophoresis of the amplicons was done at 100 volts for 35 minutes in $1 \mathrm{X}$ Tris-borate-EDTA buffer in $1.5 \%$ agar gel, stained with ethidium bromide and visualized by UV transilluminator. Band size was assessed by comparing with bands of $100 \mathrm{bp}$ DNA ladder. 
DNA sequencing: Amplified DNA was purified by PCR Purification Kit (Favorgen, Biotech Corp,Taiwan) according to manufacturer's instruction. Purified DNA was then sequenced in ABI C500 gene sequencer. The sequence of the amplified DNA was compared with gyrA DNA sequence available in gene bank and mutation site of DNA and subsequently mutated protein was identified.

\section{RESULT}

Of the 323 blood samples, 11(3.41\%) Salmonella typhi and 19(5.88\%) Salmonella paratyphi A were isolated. On antimicrobial susceptibility tests, $8(72.73 \%)$ Salmonella typhi and 19(100\%) Salmonella paratyphi A were resistant to nalidixic acid (Table-1). All the Salmonella typhi and Salmonella paratyphi A were positive for gyrA gene (fig.1) DNA sequencing of quinolone resistance-determining region of gyrA gene of nalidixic acid sensitive (fig.2) and nalidixic acid resistant Salmonella typhi and Salmonella paratyphi A (fig.3) showed mutation at amino acid position 83(TCC, coded for serine was replaced by TTC, coded for phenylalanine). None of the nalidixic acid sensitive strains showed mutation of amino acid at position 83 (Table-2).

Table-1 Antimicrobial resistance pattern of Salmonella typhi and S. Paratyphi A.

\begin{tabular}{lcc}
\hline Antimicrobial agent & $\begin{array}{c}\text { S.typhi } \\
\mathbf{n}(\%)\end{array}$ & $\begin{array}{c}\text { S. paratyphi A } \\
\mathbf{n}(\%)\end{array}$ \\
\hline Ciprofloxacin & $2(18.18)$ & $3(15.79)$ \\
Nalidixicacid & $8(72.73)$ & $19(100)$ \\
Ofloxacin & $1(9.09)$ & $4(21.05)$ \\
\hline
\end{tabular}

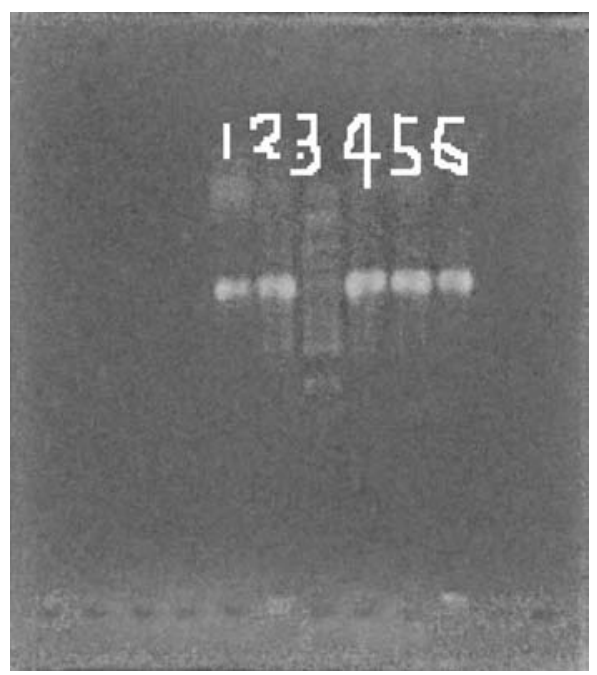

Figure 1. Photograph of gyrA gene amplified from Salmonella typhi (lane $1 \& 2$ ), Salmonella paratyphi A (lane 4,5\&6) and 100 bp DNA ladder (lane 3)
136 NNNGGGAATCCGACTTACGCATGACGTATTGGGCATGAC

175 TGGAACAAAGCCTATAAAAAATCTGCCCGTGTCGTTGGTG

216 ACGTAATCGGTAAATACCATCCCCACGGCGATTCCGCAGT

256 GTATGACACCATCGTTCGTATGGCGCAGCCATTCTCGCTG

296 CGTTACATGCTGGTGGATGGTCAGGGTAACTTCGGTTCTA

336 TTGACGGCGACTCCGCGGCGGCAATGCGTTATACGGAGAT

376 CCGTCTGGCGAAAATCGCCCACGGACTGATGGCCGATCT

415 CGAAAAAGAGACGGTGGATTTCGTGGATAACTATGACGG

454 TACGGAAAAAATTCCGGACGTCATGCCGACCAAAATTCC

493 GAATCTGCTGGTGAACGGTTCTTCCGGTATCGCAGTAGGT

533 ATGGCGACGAATATCCCGCCGCACAACCTGACGGAAGTC

572 ATCAACGANNN

Fig-2. DNA sequence of quinolone resistance-determining region of gyrA gene of nalidixic acid sensitive Salmonella typhi with highlighted base sequence coded for amino acid ( serine) at position 83 ( mutation of which causes nalidixic acid resistance).

136 NNNGGGAATCCGACTTACGCATGACGTATTGGGCATGAC 175 TGGAACAAAGCCTATAAAAAATCTGCCCGTGTCGTTGGTG 216 AATCGGTAAATACCATCCCCACGGCGATTTCGCAGT 256 TGACACCATCGTTCGTATGGCGCAGCCATTCTCGCTG

Fig-3. Partial DNA sequence of quinolone resistancedetermining region of $g y r A$ gene of nalidixic acid resistant Salmonella typhi and Salmonella paratyphi $A$ with highlighted area of mutation at amino acid position 83. Due to point mutation, cytosine ( C ) is substituted with thymine (T), as a result, TCC, which is coded for serine was replaced by TTC, which is coded for phenylalanine.

Table-2 Detection of mutated gyrA gene from nalidixic acid resistant $S$. typhi and $S$. paratyphi $A$ by sequencing of amplified DNA.

\begin{tabular}{|c|c|c|c|c|}
\hline DNA & category & $\begin{array}{l}\text { Position of } \\
\text { mutation }\end{array}$ & $\begin{array}{l}\text { Changes in base } \\
\text { sequence }\end{array}$ & $\begin{array}{l}\text { Changes in } \\
\text { amino acid }\end{array}$ \\
\hline S.typhi & sample & Serine-83 & TCC to TTC & $\begin{array}{l}\text { Serine to } \\
\text { phenylalanine }\end{array}$ \\
\hline S.paratyphi A & sample & Serine-83 & TCC to TTC & $\begin{array}{l}\text { Serine to } \\
\text { phenylalanine }\end{array}$ \\
\hline S.typhi/S.paratyphiA & Control & Serine- 83 & TCC-on charge & Serine-no charge \\
\hline
\end{tabular}

Note: T=Thymine, C=Cytosine, $S$. typhi and $S$. paratyphi $A$ sample $=$ nalidixic acid resistant strains, $S$. typhi/S. paratyphi $A$ control $=$ nalidixic acid sensitive strains .

\section{DISCUSSION}

Despite the use of antibiotics and development of newer antimicrobial agents, enteric fever remains major public health problem in developing countries due to resistance to conventional antibiotics (ampicillin, chloramphenicol and cotrimoxazole) and treatment failure with fluoroquinolones. 
Increased isolation of nalidixic acid resistant Salmonella indicates that fluoroquinolones are no more treatment option for enteric fever.

In this study culture yielded growth of Salmonella typhi in $3.41 \%$ and S.paratyphi $A$ in $5.88 \%$ of the clinically suspected enteric fever cases which is similar to other studies in Nepal ${ }^{12}$ and India ${ }^{13}$.

In consistent with other studies of India $14,15,72.73 \%$ Salmomella typhi were resistant to nalidixic acid in the present study. In addition, $18.18 \%$ Salmonella typhi were resistant to ciprofloxacin which is similar to published data from India ${ }^{3}$ and $\mathrm{Nepa}^{16}$. In contrast, $34.5 \%$ ciprofloxacin resistant strains were reported from New Delhi ${ }^{17}$. About 9.09\% Salmonella typhi were resistant to ofloxacin in this study which agrees with other reports from India ${ }^{14,18}$ but does not correlate with data of Pakistan where $88.2 \%$ Salmonella were resistant to ofloxacin ${ }^{19}$. The dissimilarity of resistance pattern of Salmonella typhi to ciprofloxacin and ofloxacin between our study and other studies might be due to difference in use of antibiotics to treat enteric fever in different countries and different areas of the same country. Moreover, these are orally administered drugs which are prescribed by the physicians and used by the people due to its easy availability for treatment of other infections, which may play role in development of drug resistance against Salmonella.

All (100\%) Salmonella paratyphi A were resistant to nalidixic acid in this study which is similar to other studies in India and Nepal ${ }^{17,20}$. Dissimilarity was noted by Shetty et al (2012) in India who reported $62.5 \%$ Salmonella paratyphi A were resistant to nalidixic acid. About $15.79 \%$ strains were resistant to ciprofloxacin which is similar to studies in India ${ }^{3,21}$. In contrast, $1.56 \%$ strains resistant to ciprofloxacin was reported from India ${ }^{22}$. Ofloxacin was ineffective in $21.05 \%$ Salmonella paratyphi strains in this study which is similar with a study in Pakistan ${ }^{23}$ but does not correlate with data of another study in Pakistan ${ }^{19}$ where $83.9 \%$ Salmonella paratyphi were resistant to ofloxacin.

From these findings it seems that proportion of ciprofloxacin resistance is less in vitro, but as most of the Salmonella typhi and $100 \%$ Salmonella paratyphi $A$ are resistant to nalidixic acid in this study, so ciprofloxacin and other quinolones will not be effective in vivo.

In both Salmonella typhi and Salmonella paratyphi A, gyrA gene was mutated on amino acid position 83 and serine was replaced by phenylalanine. This data is similar to data reported from Vietnam ${ }^{24}$, some parts of $\mathrm{Asia}^{25}$ where same mutation at position 83 of $g y r A$ gene was observed in 78.9 to 100\% Salmonella typhi strains but dissimilar with a report from China ${ }^{26}$ where $30 \%$ Salmonella were found mutated at amino acid position 87 of gyrA gene. For Salmonella paratyphi $A$, similar data were reported from different regions where $95-100 \%$ Salmonella paratyphi $A$ were mutated at amino acid position $83^{27,28}$. In contrast to the present findings it was reported from China that $16 \%$ Salmonella paratyphiA were mutated at amino acid position 87 of gyrA gene ${ }^{28}$. The amino acids serine at position 83 and aspartic acid at position 87 of gyrase are necessary for sensitivity with nalidixic acid 29 . We, however, did not find any mutation at position 87 .

\section{CONCLUSION}

Salmonella paratyphi A was predominant over Salmonella typhi as a causative agent of enteric fever. Most of the Salmonella typhi and $100 \%$ Salmonella paratyphi A were resistant to nalidixic acid and the resistance was due to mutation at amino acid position 83 of gyrase protein by replacing serine with phenylalanine.

\section{REFERENCES}

1. Khan MN, Shafee M, Hussain K, Samad A, Awan MA, Manan A et al. Typhoid fever in paediatric patients in Quetta, Balochistan, Pakistan. Pak J Med Sci. 2013; 29(4):929-932.

2. Teh CSJ, Chua KH and Thong KL. Paratyphoid fever: splicing the global analyses. Int J Med Sci. 2014; 11(7):732-741.

3. Dutta S, Das S, Mitra U, Jain P, Roy I, Ganguly SS et al. Antimicrobial resistance, virulence profiles and molecular subtypes of Salmonella enterica serovars Typhi and Paratyphi A blood isolates from Kolkata, India during 2009-2013. PLoS ONE. 2014; 9(8): e101347.

4. Rahman M, Siddique AK, Shoma S, Rashid H, Salam MA, Ahmed QS et al. Emergence of multidrug-resistant Salmonella enterica serotype Typhi with decreased ciprofloxacin susceptibility in Bangladesh. Epidemiol Infect. 2006; 134: 433-438.

5. Kumar M, Dahiya S, Sharma P, Sharma S, Singh TP, Kapil A et al. Structure based in silico analysis of quinolone resistance in clinical isolates of Salmonella Typhi from India. PLoS ONE. 2015; 10(5): e0126560.

6. Tatavarthy A, Sanderson R, Peak K, Scilabro G, Davenhill $\mathrm{P}$, Cannons A et al. Molecular typing and resistance analysis of travel-associated Salmonella enterica serotype Typhi. J Clin Microb. 2012; 50(8): 2631-2638.

7. Giraud E, Brisabois A, Martel J and Chaslus-Dancla E. Comparative studies of mutations in animal isolates and experimental in vitro- and in vivo-selected mutants of Salmonella spp. suggest a counter selection of highly 
fluoroquinolone-resistant strains in the field. Antimicrob Agents Chemther. 1999; 43(9): 2131-2137.

8. Hakanen A, Kotilainen P, Jalava J, Siitonen A and Huovinen P. Detection of decreased fluoroquinolone susceptibility in Salmonellas and validation of nalidixic acid screening test. J Clin Microb. 1999; 37(11): 3572-3577.

9. Clinical and Laboratory Standards Institute. Performance standards for antimicrobial susceptibility testing. Informational supplement M100-S23. Clinical and Laboratory Standards Institute, Wayne, PA. 2013.

10.Murray PR, Baron EJ, Jorgensen JH, Landry ML and Pfaller MA. Manual of Clinical Microbiology. 9thed. ASM press, Washington, D.C. 2007.

11.Farzana R, Shamsuzzaman SM, Mamun KZ and Shears P. Antimicrobial susceptibility pattern of extended spectrum b-lactamase producing gram-negative bacteria isolated from wound and urine in a tertiary care hospital, Dhaka city, Bangladesh. Southeast Asian J Trop Med Public Heath.2013;44(1):96-103.

12.Pokharel P, Rai SK, Karki G, Katuwal A,Vitrakoti R and Shrestha SK. Study of enteric fever and antibiogram of Salmonella isolates at a teaching hospital in Kathmandu Valley. Nepal Med Coll J. 2009; 11:176-178.

13.Palit A, Ghosh S, Sanjucta D, Sur D, Bhattacharya MK, Bhattacharya SK. Increasing prevalence of Salmonella enterica serotype Paratyphi A in patients with enteric fever in a periurban slum setting of Kolkata, India. Int $\mathbf{J}$ Environ Health Res. 2006; 16(6):455-459.

14.Menezes GA, Harish BN, Khan MA, Goessens WHF and Hays JP. Antimicrobial resistance trends in blood culture positive Salmonella Typhi isolates from Pondicherry, India, 2005-2009. Clin Microbiol Infect. 2012; 18: 239-245.

15.Harish BN and Menezes GA. Preserving efficacy of chloramphenicol against typhoid fever in a tertiary care hospital, India. Reg Health For, 2011; 15: 92-96

16.Karki S, Shakya P, Cheng AC, Dumre SP and Leder K. Trends of etiology and drug resistance in enteric fever in the last two decades in Nepal: a systematic review and meta-analysis. Clin Infect Dis. 2013; 57(10): e167-76.

17.Jain S and Chugh TD. Antimicrobial resistance among blood culture isolates of Salmonella enterica in New Delhi. J Infect Dev Ctries. 2013; 7(11): 788-795.

18.Lakshmi V, Ashok R, Susmita J and Shailaja VV. Changing trends in the antibiograms of Salmonella isolates at a tertiary care hospital in Hyderabad. Indian $\mathrm{J} \mathrm{Med}$ Microbiol. 2006; 24 (1): 45-48.

19.Qamar FN, Azmatullah A, Kazi AM, Khan E and Zaidi AKM. A three-year review of antimicrobial resistance of Salmonella enterica serovars Typhi and Paratyphi A in Pakistan. J Infect Dev Ctries. 2014; 8(8):981-986.
20.Chand HJ, Rijal KR, Neupane B, Sharma VK and Jha B. Re-emergence of susceptibility to conventional first line drugs in Salmonella isolates from enteric fever patients in Nepal. J Infect Dev Ctries. 2014; 8(11):1483-1487.

21. Muthu G, Suresh A, Kumar ES, Vishnuprabu D, Rajan A, Mary $\mathrm{S}$ et al. Molecular analysis of gyrA mutations in Salmonella paratyphi $A$ by PCR-RFLP and sequencing method. Int J Pharm Sci. 2014; 6(5):658-660.

22. Bhattacharya SS, Das U and Choudhury BK. Occurrence \& antibiogram of Salmonella Typhi \& S. Paratyphi A isolated from Rourkela, Orissa. Indian J Med Res. 2011; 133(4):431-433.

23. Hasan R, Zafar A, Abbas Z, Mahraj V, Malik F and Zaidi A. Antibiotic resistance among Salmonella enterica serovars Typhi and Paratyphi A in Pakistan (2001-2006). J Infect Dev Ctries.2008; 2(4): 289-294.

24. Holt KE, Dolecek C, Chau TT, Duy PT, La TTP, Hoang NVM et al. Temporal fluctuation of multidrug resistant Salmonella Typhi haplotypes in the Mekong river delta region of Vietnam. PLoS Negl Trop Dis. 2011; 5(1): e929.

25. Chau TT, Campbell JI, Galindo CM, Hoang NVM, Diep TS, Nga TTT et al. Antimicrobial drug resistance of Salmonella enterica serovar Typhi in Asia and molecular mechanism of reduced susceptibility to the fluoroquinolones. Antimicrob Agent Chemother. 2007;51(12): 4315-4323.

26. Wu W, Wang H, Lu J, Wu J, Chen M, Xu Y et al. Genetic Diversity of Salmonella enterica serovar Typhi and Paratyphi in Shenzhen, China from 2002 through 2007. BMC Microb. 2010; 10(32): http://www.biomedcentral.com/1471-2180/10/32.

27. Hirose K, Hashimoto A, Tamura K, Kawamura Y, Ezaki $\mathrm{T}$, Sagara $\mathrm{H}$ et al. DNA sequence analysis of DNA gyrase and DNA topoisomerase IV quinolone resistancedetermining regions of Salmonella enterica serovar Typhi and serovar Paratyphi A. Antimicrob Agent Chemother.2002; 46(10): 3249-3252 .

28.Song Y, Roumagnac P, Weill F, Wain J, Dolecek C, Mazzoni CJ et al. A multiplex single nucleotide polymorphism typing assay for detecting mutations that result in decreased fluoroquinolone susceptibility in Salmonella enterica serovars Typhi and Paratyphi A. J Antimicrob Chemother. 2010;65: 1631-1641

29.Aldred KJ, Kerns RJ and Osheroff N. Mechanism of quinolone action and resistance. Biochem. 2014; 53:1565-1574. 